\title{
A Batalha do Livramento: exposição e silenciamento entre os Tembé-Tenethara
}

\author{
Battle of Livramento: \\ exposure and silence between the Tembé-Tenethara
}

Nassif Ricci Jordy Filho

Universidade Federal do Pará

https://orcid.org/0000-0002-7676-8126

Ivânia dos Santos Neves Universidade Federal do Pará

http://orcid.org/0000-0002-6738-5254

\begin{abstract}
Resumo: Em 1996, um grupo de 77 Tembé-Tenetehara da Terra Indígena Alto Rio Guamá foi aprisionado por fazendeiros invasores de suas terras no estado do Pará. Durante três dias foram submetidos à tortura e à falta de condições mínimas para sobreviver e o grau de violência explícita deste caso produziu repercussão na mídia local e nacional. Depois de liberados, no entanto, houve um silenciamento sobre este acontecimento que só se interrompeu em 2014, com a realização da pesquisa Patrimônio Cultural Tembé-Tenetahara. Neste artigo, analisamos discursivamente as emergências históricas deste acontecimento, a partir das narrativas políticas dos Tembé-Tenetehara e das fotografias publicadas na cobertura dos jornais impressos. Tomamos como referência teórica as formulações de acontecimento, intericonicidade, redes de memória e memória subterrânea.
\end{abstract}

Palavras-Chaves: Dispositivo Colonial, Resistência, Conflitos de Terra.

Abstract: In 1996, a group of 77 Tembé-Tenetehara from the Alto Rio Guamá Indigenous Land was arrested by invading farmers from their lands in the state of Pará. During three days they were subjected to torture and the lack of minimum conditions to survive and the degree of explicit violence in this case had repercussions in local and national media. After they were released there was a silencing of the event that was only interrupted in 2014, to research Patrimônio Cultural Tembé-Tenetahara. In this article, we discursively analyze the historical emergencies of this event, from the political narratives of Tembé and from the photographs published in the frontpages of newspapers. We will take as theoretical reference the formulations of events, intericonicity, memory net and underground memory.

Keywords: Colonial Dipositive, Resistance, Earth Conflicts 


\section{Introdução}

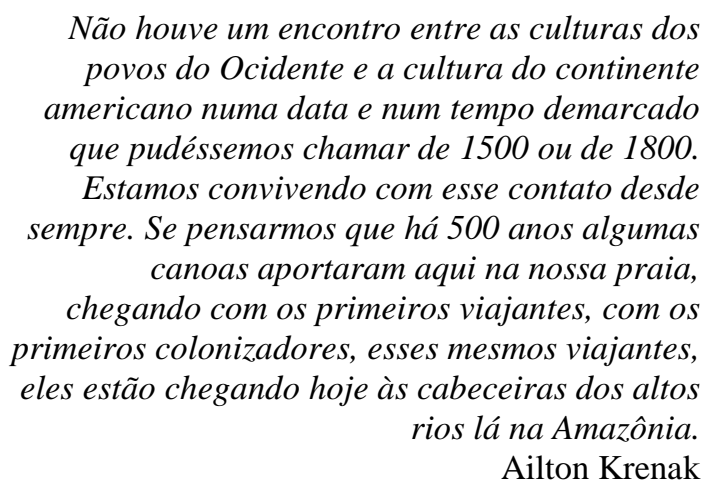

A racionalidade ocidental, sistematicamente, nos últimos cinco séculos estabeleceu uma forma de contar a história presa a uma única temporalidade com princípio, meio e fim, supostamente fixa, sem a possibilidade de outras versões ou outros lugares de enunciação. Sempre houve, no entanto, quem resistisse a esta produção de verdade institucionalizada e ainda hoje sustentada a partir de saberes e poderes que a transformaram num discurso hegemônico. Como resultado deste embate, mesmo nas universidades e centros de pesquisas ocidentais, sabemos hoje que o trabalho da memória não se submete totalmente a esta imposição.

O acontecimento discursivo que analisamos remonta a 1996: um grupo de 77 Tembé-Tenetehara da Terra Indígena Alto Rio Guamá- TIARG foi aprisionado por fazendeiros invasores de suas terras no estado do Pará. Durante três dias foram submetidos à tortura e à falta de condições mínimas para sobreviver. O grau de violência explícita deste caso produziu repercussão na mídia local e nacional. Surpreendentemente, desde então, não apareceu nem em reportagens e em nenhum dos muitos trabalhos acadêmicos produzidos sobre os Tembé qualquer referência a este acontecimento.

Por que agora é possível falar sobre o que aconteceu em 1996? "Porque só vocês quiseram nos ouvir", respondeu o cacique da aldeia Sede Naldo Tembé à pergunta feita por Ivânia Neves, durante a realização do projeto Patrimônio Tembé ${ }^{1}$, na TIARG, no segundo semestre de 2014, depois do cacique nos contar sobre este acontecimento que

\footnotetext{
${ }^{1}$ Este projeto, financiado pelo IPHAN, nasceu de uma solicitação dos próprios Tembé-Tenetehara, em 2008. Eles desejavam a confecção de um livro sobre seu patrimônio cultural, pois embora já houvesse uma série de documentários e trabalhos acadêmicos sobre este povo, eles não se reconheciam. Organizamos, entre dezembro de 2013 a março de 2017,uma série de projetos de pesquisa e extensão entre eles, que resultou, entre outras produções, no livro "Patrimônio Cultural Tembé-Tenetehara" (NEVES; CARDOSO, 2015), na dissertação "Narrativas Orais Tembé-Tenetehara: percursos etnográficos, memórias e resistências”(JORDY FILHO, 2016) e no documentário “ A Batalha do Livramento" (JORDY FILHO, 2018).
} 
também ficou conhecido como "A Batalha do Livramento". Visibilizá-lo tantos anos depois é colocar em evidência saberes sujeitados, "blocos de saber histórico que estavam presentes e mascarados no interior dos conjuntos funcionais e sistemáticos e que a crítica pode fazer reaparecer, evidentemente através do instrumento da erudição" (FOUCAULT, 1999, p.96).

Quando nos contaram sobre a narrativa, eles sabiam o nosso lugar de enunciação, o que fazíamos entre eles e quais eram os nossos interesses: escrever um livro que contasse a versão Tembé da história de sua sociedade e dos conflitos do contato com os não indígenas. Foram eles que solicitaram ao IPHAN - Instituto do Patrimônio Histórico e Artístico Nacional, a pesquisa que resultaria no livro "Patrimônio Cultural Tembé-Tenetehara" (NEVES; CARDOSO, 2015). Construímos uma relação de respeito mútuo. A princípio, procurávamos materialidades da tradição do povo Tembé-Tenetehara, como narrativas cosmológicas, artesanias, música, danças, pinturas corporais, etc. Estas materialidades, presentes na memória coletiva dos TembéTenetehara, de certa forma, se emaranhavam com as memórias de luta desse povo com as dos não indígenas.

Dentro dessas condições de possibilidade históricas, a memória do sequestro, aprisionamento e tortura de 77 Tembé-Tenetehara, em 1996, foi trazida das sombras. Este acontecimento é a história de um conflito dentro de outros, nesta constante luta dos Tembé para garantirem a posse de suas terras. Ele é um nó discursivo numa história mais ampla de violência, que envolve os povos indígenas desde o início da colonização. Para entender esta história "só se pode fazê-la corretamente sob a condição de que se esteja ligado, de uma maneira ou de outra, aos combates que se desenrolam nesse domínio" (FOUCAULT, 2008, 245).

Tomamos as narrativas orais dos Tembé e os recortes de jornais da época, com suas fotografias bastante significativas, como enunciados fundamentais para analisar discursivamente este acontecimento. Elas apresentam as condições de emergências históricas que favoreceram o aprisionamento dos 77 indígenas e as relações de saber e poder que implicaram em um silenciamento deste acontecimento no âmbito acadêmico. Baseados no método arqueológico proposto por Michel Foucault (2005), procuramos analisar os processos de visibilidade e silenciamento dos enunciados que envolvem a Batalha do Livramento e para isso também consideramos o conceito de memória subterrânea de Michel Pollak (1989). Na análise das imagens, consideramos a definição 
de intericonicidade proposta por J.J. Courtine (2011), para observar como as fotografias colocadas em circulação pelos jornais retomam a memória de outras imagens.

\section{Sobre os Tembé-Tenetehara}

A história Tembé-Tenetehara, desde o primeiro contato com os karaiw (caraíba, de raiz etimológica caribe, por conta, talvez, do local/língua já colonizado/a e aniquilado/a de onde se já ouvia falar, as ilhas da América Central), é de luta e de diáspora. A partir do início da colonização da Amazônia pelos portugueses, iniciada em 1614, com a fundação de São Luís, seguida pela fundação de Belém dois anos depois, o rolo compressor da colonização começou a passar por cima deles, pois eles e os Tupinambá eram os senhores desta parte do litoral. Para conseguir sobreviver, gradativamente precisaram se afastar do litoral.

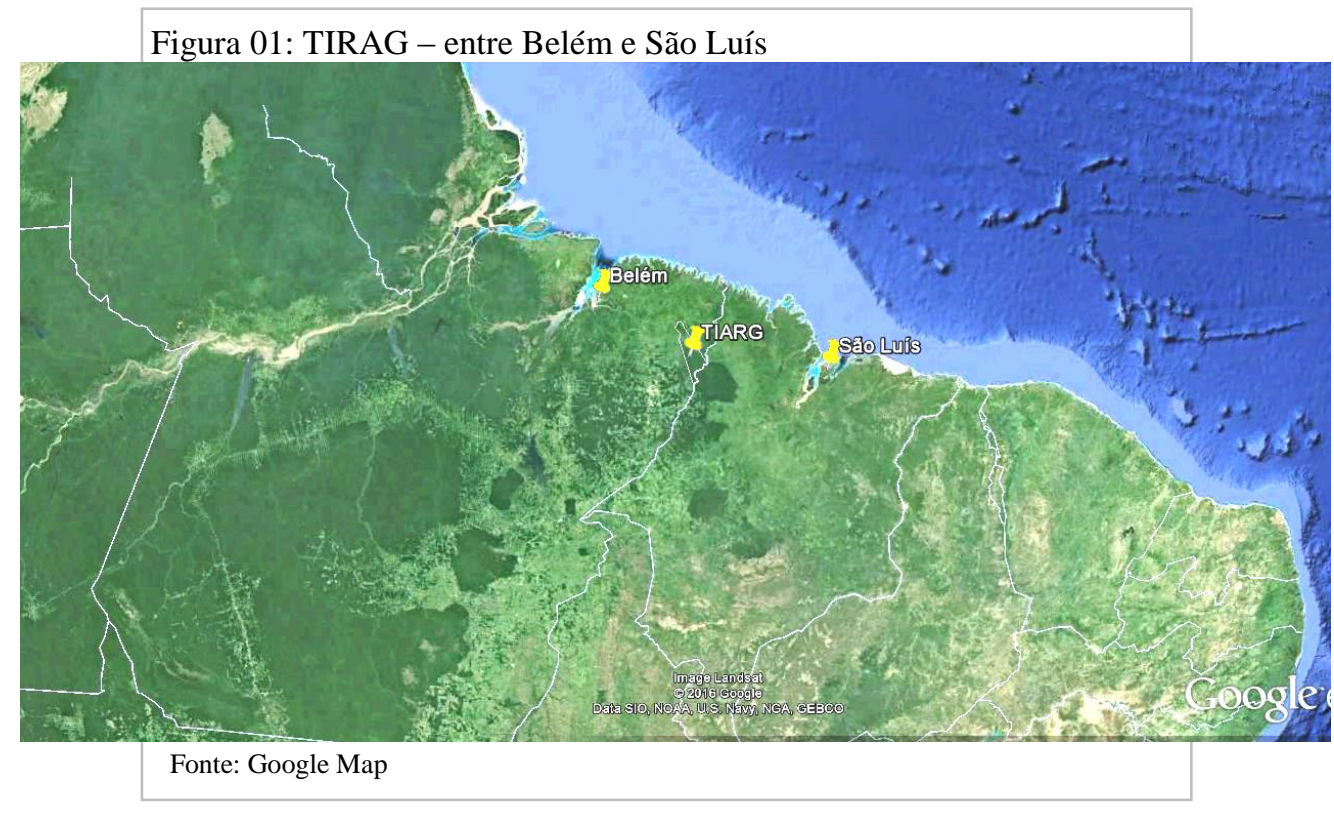

Em meados do século XIX, grande parte dos Tenetehara rumou do Alto Rio Pindaré e Rio Caru, no Maranhão, em direção aos rios Gurupi, Guamá e Moju, já no estado do Pará (que significa "rio" no tronco linguístico Tupi). Os próprios Tembé nos contam que o contato existe há muitos séculos e que seus antepassados vinham de rio em rio fugindo dos karaiw.

Depois de um histórico de muitas lutas e reconfigurações, hoje, sem muita dificuldade, os Tembé do rio Gurupi visitam os parentes mais ao norte, no rio Guamá, e vice-versa. Na história recente desse povo, isso só recomeçou a acontecer com mais frequência a partir de 2015, quando a Justiça determinou, após 35 anos de tentativas, a 
desintrusão da Fazenda Mejer. As ações deste grande fazendeiro russo envolveram a ocupação de uma grande área de terra e a construção de uma estrada, fortemente vigiada com homens armados, que por quase 20 anos dividiu o povo em Tembé do Gurupi e Tembé do Guamá.

Os Tembé-Tenetehara vivem atualmente na Amazônia oriental, no leste do estado do Pará. Eles estão divididos, segundo dados do Instituto Socioambiental ${ }^{2}$, em sete Terras Indígenas: Alto Rio Guamá (TIARG - sigla que passará a ser usada daqui em diante no texto); Alto do Turiaçu; Tembé; Turé-Mariquita; Turé-Mariquita II; Marakaxi; Jeju e Areal. Em cada Terra indígena mencionada, o conflito com a sociedade envolvente é constante.

Naldo Tembé estima que, atualmente, a população na TIARG seja de aproximadamente 2000 Tembé-Tenetehara, além de alguns indivíduos de outras sociedades, como da etnia Guajajara, povo também Tenetehara que vive no Maranhão, Ka'apor, sociedade pejorativamente conhecida como urubu, que durante séculos evitavam os encontros com os Tembé por lhes acharem muito agressivos, ou dos Timbira.

Outra consequência bastante negativa do contado deste povo com os não indígenas está presente nos nomes próprios e nas denominações dos territórios onde habitam, impostas aos povos indígenas, cujas autodenominações até a Constituição de 1988 foram sistematicamente interditadas. "Muitos receberam e ficaram conhecidos por nomes que lhes foram dados por seus próprios inimigos." (PEREIRA GOMES, 2002, 49). A autodenominação Tenetehara significa "o homem verdadeiro" ou "o homem de verdade", não no sentido daquele que carrega a verdade, mas de gente real, de carne e osso.

Segundo Sérgio Muxi, cacique da aldeia Tekohaw no Gurupi, eles também se autodenominam Y'riwara, o povo da água, das margens e beiras dos rios, em oposição a algumas sociedades que são Ka'awara, ou seja, de dentro da mata. "Em seus processos migratórios, sempre seguiram o contorno dos leitos dos rios. "Y" significa água e Y'riwara significa povo da água” (NEVES; CARDOSO, 2015, 37).

Dividimos suas narrativas em dois grandes grupos: a) as cosmológicas, que explicam a criação do universo, das pessoas, dos rituais e se inscrevem na temporalidade da língua Tenetehara, cuja marcação principal é Kwehe Dkwehe, e b) as 
narrativas políticas, voltadas aos conflitos do contato, desenhadas pela imposição da língua portuguesa, pelas invasões de terra, pelas dificuldades com a saúde indígena entre outros. A história contada pelos Tembé sobre a Batalha do Livramento é um exemplo dessas narrativas políticas.

A língua Tenetehara, junto com outras 21, faz parte da grande família TupiGuarani. Os Tembé e os Guajajara, que vivem no Maranhão e interagem bastante, são as duas sociedades falantes atuais desta língua. Os Tembé são um povo de língua e tradição tupi. Isso significa dizer que, além de fazerem parte do tronco linguístico Tupi, dentro da família linguística tupi-guarani, eles compartilham, entre si e com outras etnias, uma memória Tupi, que apesar de muitas diferenças, está presente nas histórias, nas constelações, na palha das edificações tradicionais, nos sentidos do maracá, nos traços do grafismo, nos adereços corporais.

Os Tembé com quem estabelecemos processos de interação vivem entre as 12 aldeias do Rio Guamá, ao norte da Terra Indígena Alto Rio Guamá (TIARG), entre as quais, as aldeias Sede, Itaputyre e São Pedro se destacam pela maior infraestrutura (escolas, posto de saúde, etc.) e pelo maior número de moradores. Ao sul da TIARG, caracterizada pelo rio Gurupi, que faz a divisa com o estado do Maranhão, é local de outras 16 aldeias, onde Cajueiro e Tekohaw são as de maior infraestrutura.

Como veremos mais a seguir, os 77 indígenas aprisionados na vila do Livramento eram todos homens e representavam todas as aldeias que compõem a TIARG. Eles estavam juntos para fiscalizar as invasões de sua terra.

\section{A Batalha do Livramento e a narrativa Tembé}

Este acontecimento está rodeado e conectado com outros inúmeros episódios de conflitos entre os Tenetehara e o dispositivo colonial, com seus interesses econômicos, que continuam se atualizando nas fronteiras das terras indígenas. A reconstituição das redes de memória que constituem estas práticas deixa mais clara a cristalização ou emergência de um acontecimento como o dos 77 .

A noção de acontecimento, para Foucault (2008), vai de encontro à análise histórica tradicional, vê na emergência do fato um determinado estado de forças que não obedece nem a uma destinação (teleologia) nem a uma mecânica (lógica), mas a uma aleatoriedade que está em constante mudança. As forças que se encontram em jogo na história nos revelam o acaso da luta. O que as narrativas políticas contadas pelos Tembé têm em comum, hoje, é a luta pelo território. E como uma teia, todas as histórias 
de batalha remetem à resistência e ocupação da TIARG e ao jogo discursivo que produz uma verdade ilegal que coloca este povo como invasor de suas próprias terras. Sabemos que "há um combate pela verdade, ou, ao menos entorno, da verdade", e que esta "verdade" está ligada a sistemas de poder, que a produzem e a apoiam (FOUCAULT, 2007).

Diferente das histórias oficiais, que estão nas páginas de jornal ou mais recentemente da $W e b$, nos documentos da FUNAI, nos inquéritos policiais, as narrativas políticas dos Tembé nos mostram histórias subterrâneas. Nas práticas discursivas deste povo, estes saberes produzem memórias e são enunciadas precipuamente a partir da oralidade. Segundo Pollak (1989), as narrativas orais representam um espaço singular para fazerem emergir memórias subterrâneas, sobretudo dentro de contextos ocidentais fortemente agenciados pelo texto escrito. Para este autor, a referência ao passado serve para manter a coesão dos grupos e instituições que compõem uma sociedade, a fim de defender aquilo que se tem em comum, como o território. A memória Tembé, transmitida de geração a geração, principalmente no quadro familiar, a partir da oralidade, faz parte de uma antimemória nacional, tacitamente desapercebida pela sociedade englobante.

A história que estamos analisando, o sequestro e tortura de 77 indígenas, saiu nas capas dos principais jornais paraenses, assim como em matérias de televisão veiculadas nacionalmente. Mesmo assim, é uma história que permaneceu subterrânea por muitos anos. A possibilidade de emergência desta história hoje, passando do "nãodito" à contestação e à reivindicação, nos mostra condições favoráveis para que ela aparecesse, além de nos fazer "reconhecer a que ponto o presente colore o passado" (POLLAK, 1989, p.9).

No final de maio de 1996, uma grande apreensão de madeira em uma operação conjunta entre FUNAI e IBAMA desencadeou pela segunda vez entre os Tembé a necessidade de fazer sua própria fiscalização, para tentar conter o desmatamento em suas terras. Os Tembé do Gurupi e do Guamá se juntaram com alguns Guajajara, Timbira e Ka'apor com o propósito de queimar toda a madeira apreendida, já que "a justiça sempre deixou essas madeiras com os próprios madeireiros da região, como fiel depositário. Com o passar do tempo, a madeira sumia, os bens apreendidos também sumiam" (TEMBÉ, 2015). 
Cedo da manhã, saíram três veículos com os 77 indígenas, mais três funcionários da FUNAI, e um motorista, em direção ao vilarejo do Livramento, na fronteira da TIARG, local onde estavam as madeiras apreendidas. Livramento, também chamado de Pau de Remo, é um vilarejo localizado no município de Garrafão do Norte ${ }^{3}$, que nasceu, assim como outros na área, como escoador da produção da Fazenda Mejer e ponto final

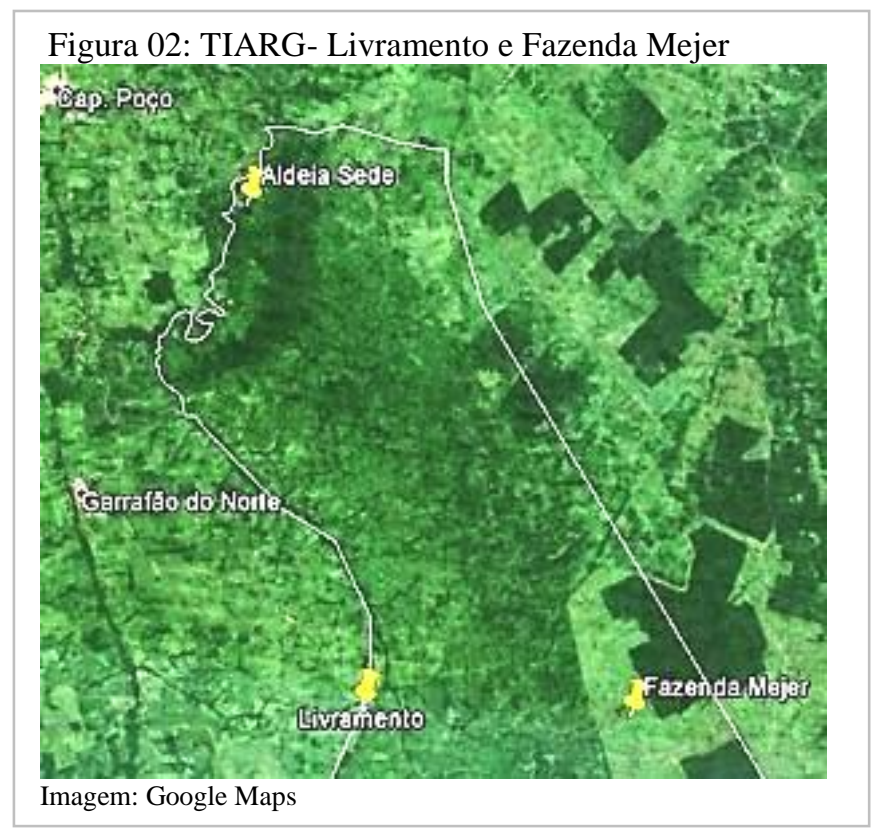

da estrada que cortou a TIARG ao meio por quase vinte anos. Esta estrada é o ponto central de todo o conflito. Em uma ponta a Fazenda Mejer, na outra o vilarejo do Livramento (Fig. 02).

\subsection{A primeira reação Tembé}

Para entender os desdobramentos iniciais desta história, vamos retomar ao ano de 1976, durante a ditadura militar, quando a estrada que dividiria a TIARG começou a ser construída pela Fazenda Mejer, com base em um acordo intermediado pela FUNAI e assinado por um grupo de Tembé que nem sabia escrever direito. A partir deste momento, o fazendeiro, com seus homens armados passaram a controlar quem poderia passar por lá, inclusive os próprios Tembé. Neste período, as aldeias Tembé eram controladas por funcionários da FUNAI, que eram os chefes dos postos localizados nas terras indígenas.

Depois do fim do governo militar, começaram os conflitos em torno e por conta da estrada, pois a fazenda já estava ocupando uma parte do território da TIARG e o

\footnotetext{
${ }^{3}$ Município do estado do Pará, a $180 \mathrm{~km}$ de Belém e a $6 \mathrm{~km}$ da borda da TIARG.
} 
fazendeiro não cumpriu o que estava no acordo inicial: abrir outra estrada em direção á aldeia Sede para o fornecimento de sementes e produtos agrícolas para os Tembé. "Eles enganaram os índios e depois que se teve uma conscientização sobre nossos direitos, começamos a mobilização" (TEMBÉ, 2015).

No início dos anos de 1980, a situação começou a mudar para os Tembé, "Quando mudou o governo, mudaram também as pessoas que trabalhavam na aldeia. Vieram pessoas que não tinham a intenção de acabar com o povo indígena e nos ajudaram a resistir a todo esse massacre.”. (TEMBÉ, 2014). É o período que começa a surgir uma resistência dentro desse sistema de controle instituído pela FUNAI através dos chefes de postos e os próprios indígenas passam a assumir o controle de suas aldeias. É momento, também, em que os Tembé decidem lutar definitivamente pelo seu território. Uma oportunidade de empoderamento para a sociedade Tembé-Tenetehara, paradoxalmente estimulada pelos novos chefes de postos.

Um dia, quando a gente estava brincando de dominó, ele ${ }^{4}$ chega e diz "Parabéns! Quem é o bom aqui no dominó?" Eu disse: "Não tem ninguém bom aqui! Estamos apenas jogando!" Ele disse "Pois é, enquanto vocês estão brincando, estão roubando a madeira de vocês! Vocês estão escutando o barulho de motosserra?". Nós discutimos logo ali, "Esse não é o papel da FUNAI? não foi esse o acordo?", eu disse. Mas mesmo assim nós nos mobilizamos. Éramos umas 15 pessoas, cada um pegou uma espingarda e fomos atrás (TEMBÉ, 2014).

Nesta ocasião, pela primeira vez os Tembé decidiram queimar a ponte que ligava a Fazenda Mejer à estrada. Naldo Tembé, com apenas 15 anos, estava presente nesta mobilização. Todos foram presos, mas logo depois soltos, a mando do delegado geral da Polícia Federal na época, Paulo Cezar, que se posicionava dentro da lei e entendia a soberania dos Tembé em seu próprio território.

No outro dia, o delegado foi de helicóptero e sobrevoou a ponte, que não pegou fogo legal. Em troca da nossa liberdade, os funcionários do Mejer colocaram fogo na nossa casa de apoio, mas o delegado mandou passar um trator pela ponte e a ponte quebrou de vez e o trator caiu no rio, mas isso custou a saída do Paulo Cezar. E a partir dali não houve mais acordo, nem respeito e a invasão se deu do dia para a noite. (TEMBÉ, 2014)

Após esse episódio, em 1986, a Fazenda Mejer invadiu definitivamente uma boa extensão de terra na TIARG e a estrada passou a ser o principal motivo de inúmeros conflitos.

\footnotetext{
${ }^{4}$ Dilson Marinho, chefe de posto da FUNAI nos anos 1990. 


\subsection{O acontecimento em si em narrativas orais}

$\mathrm{Na}$ outra ponta desta estrada, 20 quilômetros a oeste e 10 anos depois, em 1996, 77 Tembé seriam novamente presos por moradores do vilarejo Livramento, colônia abastecida principalmente pela Fazenda Mejer, por onde escoavam sua produção agrícola. Desta vez ficaram detidos por três dias e foram submetidos à tortura. Este acontecimento mexeu profundamente com todos os Tembé da TIARG. A seguir, vamos apresentá-lo a partir das narrativas de Naldo Tembé, de seu irmão Edmundo Tembé, que também fazia parte dos 77 e de sua irmã, América Tembé, à época, morando na cidade para estudar.

Nas palavras de Naldo Tembé:

Nós éramos 77 indígenas. A gente foi na área, dentro da terra indígena próximo ao vilarejo do Livramento, pra picotar e queimar as madeiras. No nosso retorno, saímos estourando tudo. Quebrando moto, bicicleta, casa. Pegando os animais das fazendas até chegar no limite da nossa terra, quase na vila do Livramento. Tinha uma ponte que ia da terra indígena pro Livramento. Passamos essa ponte para o lado de fora da terra e tocamos fogo nela. Ficamos esperando por volta de uma hora até a ponte queimar.

Só que nós tínhamos que passar pelo Livramento pra sair e quando nós saímos, encontramos um trator que estava nos esperando pra quando entrássemos na vila, ele nos cerca. Passamos com os três carros, mas o trator fechou. Quando chegamos no meio da vila tinha outra ponte, que já tinham derrubado. Voltamos, mas o trator já tinha fechado o outro lado da vila com uma tora de madeira. Caímos na água pra tentar consertar a ponte.

O pessoal da FUNAI foi em cima. Aí os colonos falaram que tínhamos que negociar. Entregar as armas pra negociar. Quando entregamos as armas, nos colocaram num galpão. Aí começaram a saquear. Tocaram fogo nos carros, chegaram com as nossas próprias armas e nos ameaçavam. (TEMBÉ, 2015).

Após a negociação com os caciques que estavam à frente, os indígenas entregaram as armas e foram conduzidos à delegacia, onde ficaram detidos em uma sala de aproximadamente 20 metros quadrados, sem espaço nem para todos sentarem e com a conveniência do delegado, lá ficaram até de manhã. A todo o momento eram ameaçados de morte. Alguns moradores, numa atitude bastante violenta, tentaram tirar as pinturas faciais feitas com jenipapo com escovinha e palha de aço e muitos Tembé ficaram com o rosto machucado. Na manhã seguinte, todos foram levados de dez em dez para outro galpão. Edmundo Tembé relata sua experiência:

Meu irmão, o Naldo, foi na primeira remessa, então eu caí logo no segundo grupo. Porque eu não sabia se eles estavam levando pra matar ou pra um galpão mesmo. Os dez primeiros não apanharam, mas os dez seguintes..., onde eu estava...já apanharam ( TEMBÈ, 2015b). 
Com um ar um tanto embaraçoso, Edmilson Tembé nos contou que ele foi um dos que mais apanhou por usar o cabelo comprido na época. Seus agressores afirmavam: "Esse aqui que índio mesmo!”...e lhe puxavam pelo cabelo.

O primeiro galpão para onde foram levados também era um espaço pequeno para os 77. Então resolveram transportá-lo todos de uma vez na carroceira de um caminhão para um segundo galpão de propriedade de um comerciante bem sucedido no vilarejo e uma das principais lideranças à frente do sequestro dos Tembé. Mais de dez mil pessoas se aglomeraram no vilarejo, a maioria com o intuito de linchamento dos Tembé "e não parava de chegar gente. Só ouvíamos falar da chegada de carrada de caminhão, ônibus, carro, vindo desses interiores próximos. Aí parente rezava, rezava. Aí eu pensava "temos que entregar na mão de deus" - conta Edmilson Tembé.

O objetivo principal dos fazendeiros era fazê-los assinar um documento em que abrissem mão da TIARG. Apesar de descumprirem tantas leis, queriam dar um ar de legalidade para as invasões. Os funcionários da FUNAI pediam que os Tembé fizessem qualquer acordo, pois sabiam que não teria validade jurídica. $\mathrm{O}$ acordo proposto exigia que Naldo Tembé, representante da região do Guamá e Valdeci Tembé, importante liderança da região do Gurupi, abrissem mão de suas terras e falassem isso em praça pública para as dez mil pessoas presentes, mas eles se recusaram.

Após três dias presos, mesmo com a Polícia Federal e Civil, além de policiais militares e todas as autoridades no local, os colonos se recusavam a soltá-los. A situação só se resolveu com a interferência da Polícia Federal, que invadiu o galpão e libertou os reféns. Durante a condução dos indígenas para um ônibus, os policiais fizeram um corredor polonês para que não houvesse mais tentativas de linchamento.

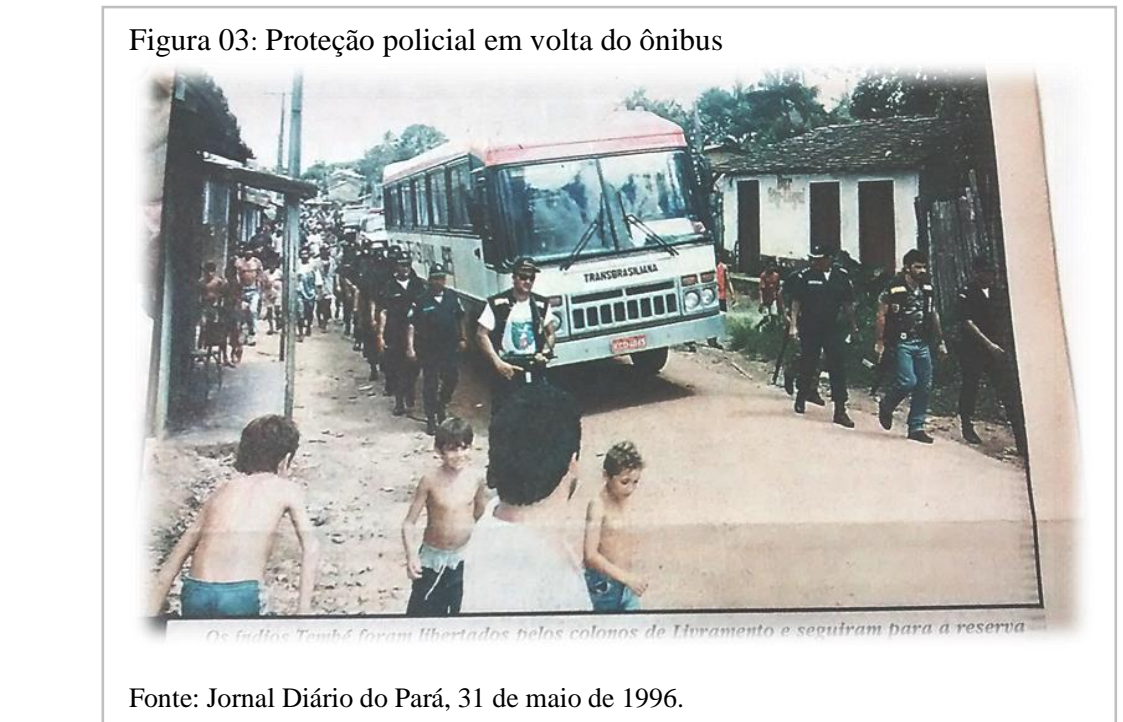


[..] em contraste com o discurso filosófico-jurídico que se ordena pelo problema da soberania e da lei, esse discurso que decifra a permanência da guerra na sociedade é um discurso essencialmente histórico-político, um discurso em que a verdade funciona como arma para uma vitória partidária, um discurso sombriamente crítico e ao mesmo tempo intensamente mítico (FOUCAULT, 1999, p.324).

As famílias Tembé souberam deste acontecimento pela mídia. Houve entre eles, mais uma vez, a plena sensação de que estavam vivendo uma guerra e seus filhos, maridos, irmãos, sobrinhos podiam não voltar desta guerra. América Tembé deu o seguinte depoimento:

Acompanhei pela televisão. Quando passou na televisão, aquela repercussão toda. Quando vi meu povo, meu pessoal, de um jeito abatido. Foi muito difícil. Eu conhecia todos. Estavam de um jeito abatido. Estavam presos num depósito. Todos sentados um perto do outro, tipo numa prisão mesmo. (TEMBÉ, 2015c)

Esta história dos 77, que está na memória do povo Tembé como um trauma, ganhou visibilidade entre eles e passou a circular nos meios acadêmicos e mesmo na mídia com o lançamento, em 2018, do documentário "A Batalha do Livramento". Sem deixar de escapar de um silenciamento mascarado, as narrativas políticas dos Tembé são histórias de luta com os não indígenas, batalhas vivenciadas não só no tempo da linguagem, mas na memória do corpo. Talvez, a derrota e a humilhação nesta batalha do Livramento tenham feito os Tembé se silenciarem por tanto tempo. Porém, foi visível a vontade que eles tiveram para falar sobre isso, o que nos demonstra que essas narrativas de guerra aparecem no momento mais oportuno para eles.

O silêncio, antes de levar ao esquecimento, "espera a hora da verdade e da redistribuição das cartas políticas e ideológicas" (POLLAK, 1989, 5). Essas genealogias, ou seja, esses acoplamentos entre a insurreição de saberes, até então encobertos e/ou desqualificados, e a eficácia da crítica local (como a própria erudição dos indígenas e a participação no jogo político da sociedade não indígena), fazem aparecer o saber histórico das lutas. As histórias de guerra, que são cicatrizes.

\section{A memória das imagens: a eterna guerra}

Toda esta movimentação em torno da Batalha do Livramento recebeu cobertura dos jornais e telejornais locais, inclusive com repercussão nacional. Houve uma intensa produção de imagens fotográficas que expuseram as condições desumanas a que os Tembé foram submetidos. Aqui vamos tomá-las como enunciados, no sentido que lhe atribui Michel Foucault (2008) para entender por que elas ganharam visibilidade em vez 
de outras. Também nos interessou entender por que ninguém se interessou em analisálas embora já haja tantos trabalhos produzidos sobre os Tembé, inclusive por eles mesmos, nos cursos de graduação a que tiveram acesso.

Para quem conhece a iconografia Tembé, as imagens mais famosas são as que registram a Festa do Moqueado, um ritual de passagem de meninas e meninos, quando ingressam na vida adulta, com seus corpos pintados de negros, ornados com penas brancas e adereços coloridos.

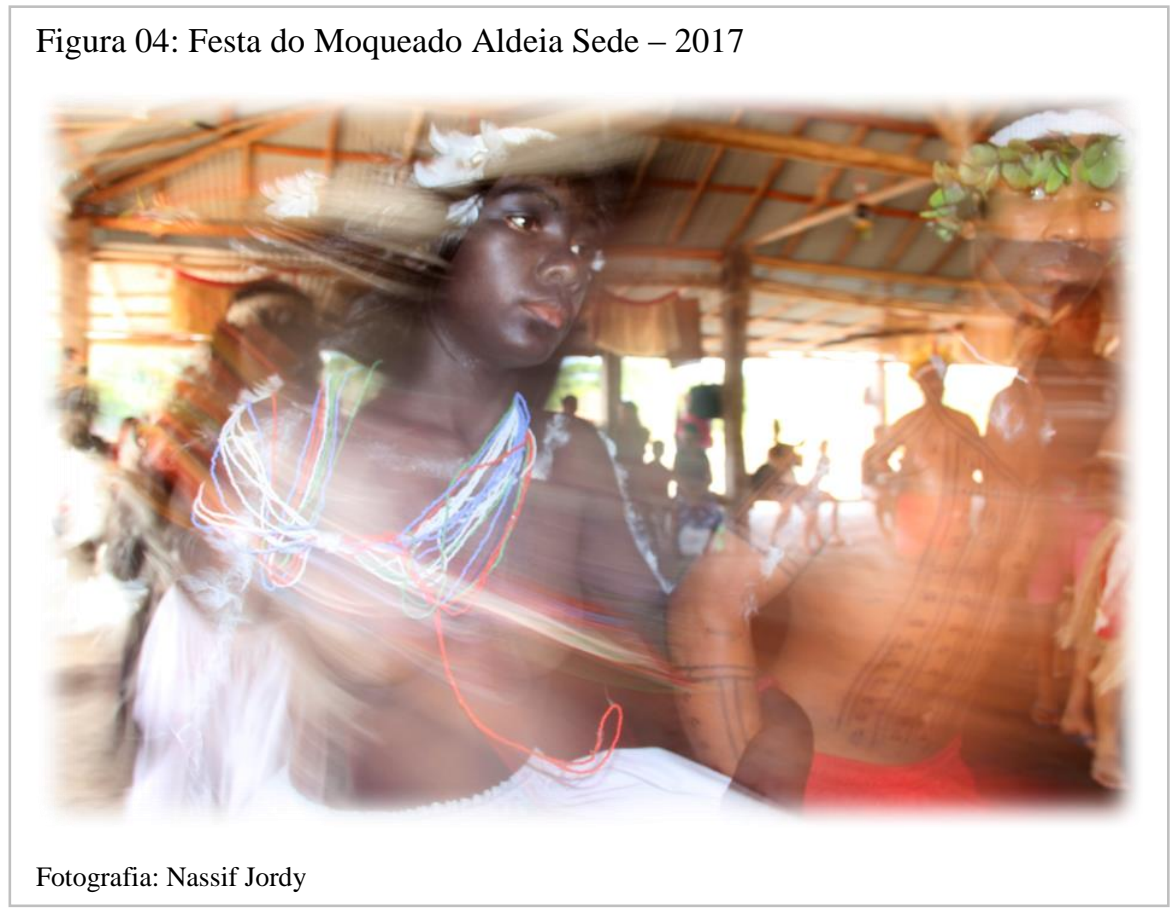

Esta imagem faz parte do repertório iconográfico de rituais de iniciação de muitas sociedades indígenas tupi, podemos dizer que ela remete a uma memória tupi Elas se encadeiam com o olhar tradicional sobre os povos indígenas. Bem diferente do que acontece com as fotografias dos jornais que fizeram a cobertura do conflito. Rosário Gregolin (2011) afirma que "primeiramente, é preciso admitir que a memória tem uma estruturação complexa, discursiva, verbal, não verbal, e de muitas materialidades, mas ela também tem um mecanismo de repetição e regularização" (GREGOLIN, 2011, p.96).

Vamos pensar as fotografias colocadas em circulação pelos dois maiores jornais impressos do estado do Pará, a partir do processo de intericonicidade, conceito formulado por J.J. Courtine (2011), que tomou como ponto de partida o método arqueológico proposto por Michel Foucault. 
A intericonicidade supõe, portanto, dá um tratamento discursivo às imagens, supõe considerar as relações entre imagens que produzem os sentidos: imagens exteriores ao sujeito, como quando uma imagem pode ser inscrita em uma série de imagens, uma arqueologia, de modo semelhante ao enunciado em uma rede de formulação, em Foucault; mas também imagens internas, que supõem a consideração de todo conjunto da memória da imagem no indivíduo e talvez também os sonhos, as imagens vistas, esquecidas, ressurgidas ou fantasiadas que frequentam o imaginário (COURTINE, 2011, p.160).

As imagens estão inseridas em uma rede de memórias, que nos remetem a outras imagens vistas ou apenas imaginadas e não estão do lado de fora do jogo discursivo. Estas fotografias retomam uma memória coletiva e, como aponta Courtine (2011) e podem ser inscritas em uma série de imagens. Vejamos a fotografia a seguir:

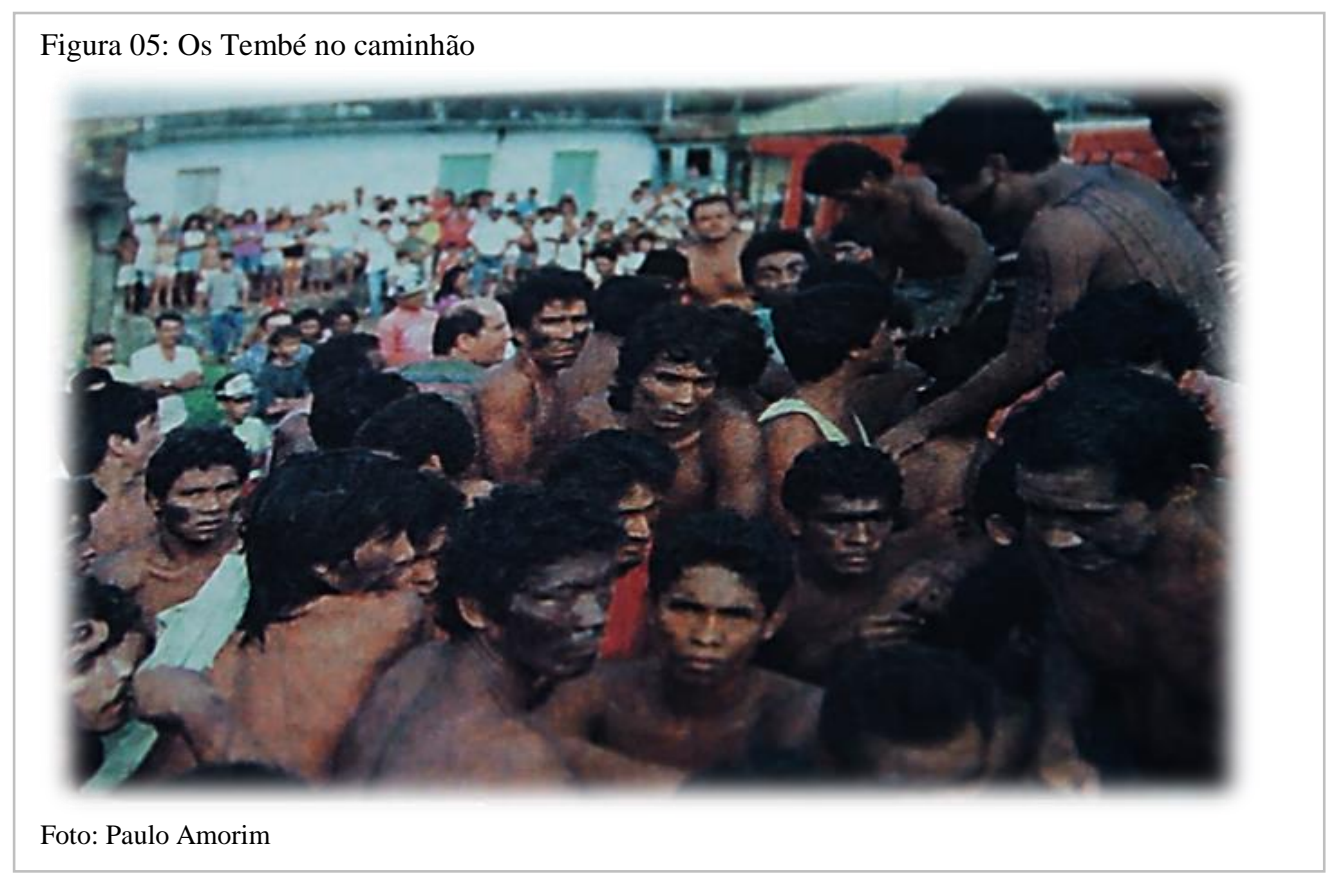

Regisitro feito por Paulo Amorim, esta foto circulou no jornal O Liberal, no dia 31 de maio de 1996. Ela flagra o momento em que os 77 Tembé foram colocados na carroceria do caminhão. A multidão em volta está toda insuflada contra os indígenas e pouco importam as condições em que eles se encontram. O cacique Naldo Tembé está no centro da fotografia, de camisa vermelha. Todos olham para as lentes do fotógrafo, talvez com esperança de denúncia, talvez com descrédito em relação às instituições ocidentais, inclusive a mídia corporativa, sempre contra eles. Podemos ver como seus corpos estão pintados com grafismo de guerra. Mais atrás, uma parte da população local interessada em um arranjo muito particular de justiça com as próprias mãos, ainda que constituída por sua grande maioria de trabalhadores do campo pobres, a serviço dos 
grandes fazendeiros, são pessoas alinhadas à memória do colonizador, para quem a vida dos indígenas não tem valor.

A imagem dos Tembé amontoados para serem transportados, não por acaso nos reporta a muitos acontecimentos profundamente destrutivos da humanidade atravessados de narrativas de violação dos direitos humanos. Ele é mais um nó discursivo numa rede de memórias visuais que nos faz relacionar as fotografias da segunda guerra, quando as pessoas eram conduzidas em espaços mínimos em vagão de trens para os campos de concentração ou ainda da iconografia dos porões dos navios negreiros.

Num país como o Brasil, certamente, a maioria da população se coloca muito mais na luta e na resistência contra esses poderes da colonialidade. Não se trata de exercer um julgamento ou se colocar em um lugar ou outro, mas considerar as inúmeras formas com que a colonialidade nos envolve. Somos uma sociedade estilhaçada, cheia de conflitos e políticas de administração das guerras que nunca encerramos (NEVES CORRÊA, 2018, p.57).

A exposição desses corpos revela que não havia pudores em deixá-los nestas condições. Por outro lado, ela também faz um apelo sensacionalista, bem ao gosto das páginas policiais e é a foto de capa. Vemos em destaque um comedouro de porcos, onde foi despejada a comida que deveria alimentá-los. Em torno dela, aglomerados pelo pequeno espaço do local, 77 Tembé se aglomeram. Sem comer adequadamente, eles estavam magros. Os colonos jogavam todo tipo de comida no chão do galpão para que eles se alimentassem e eram tratados como se fossem gado.

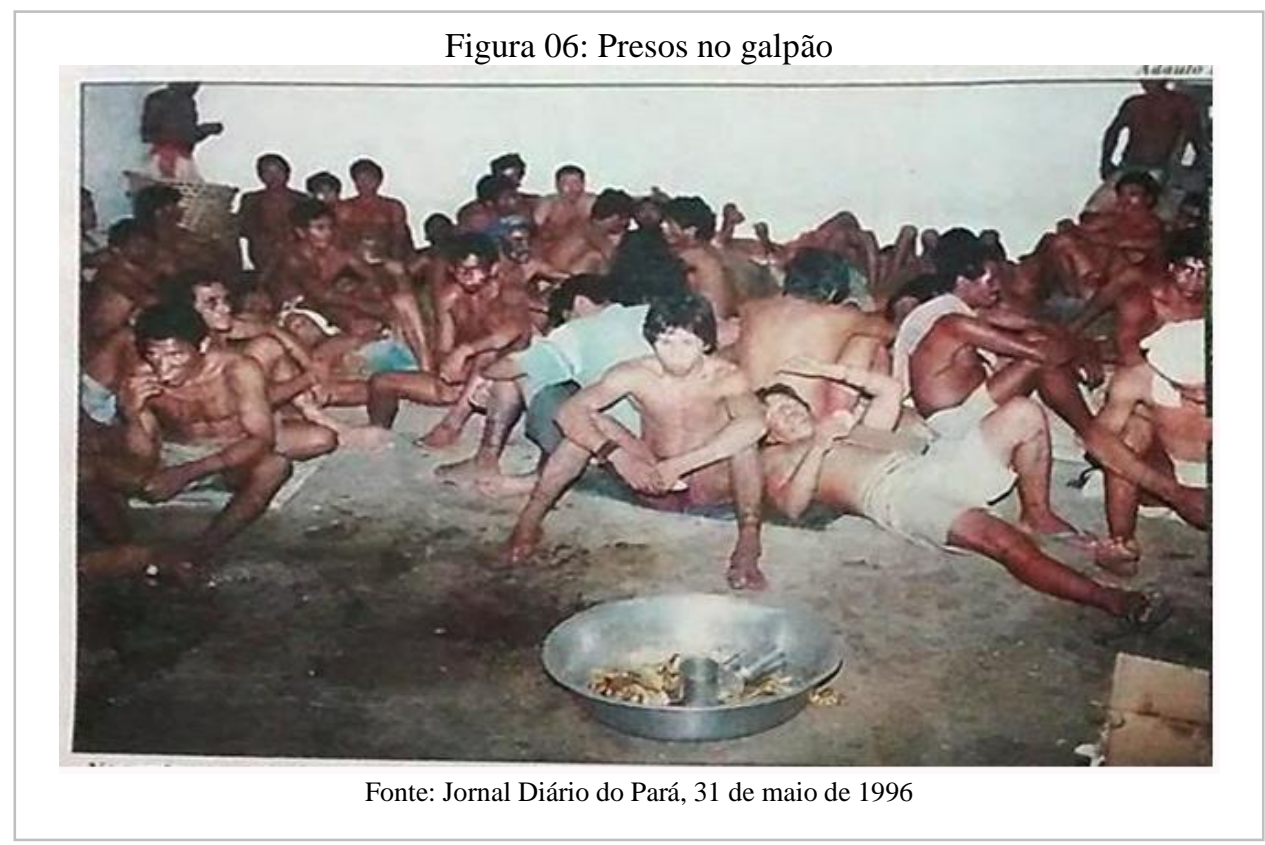


Esta imagem nos remete a um processo de intericonicidade que nos faz lembrar dos currais onde são criados porcos, bois e o comedouro reforça esta memória. Ela retoma um dos discursos mais normalizados sobre os povos indígenas, que os identifica como selvagens, sem racionalidade. Esta é uma memória da colonização ainda bastante atual entre nós. No dia 24 de janeiro de 2020, O presidente Jair Bolsonaro, falando em um vídeo em suas redes sociais sobre a criação do Conselho da Amazônia e as ações previstas para a proteção de terras indígenas, afirmou "cada vez mais, o índio é um ser humano igual a nós".

A foto produz um estranhamento, pois ao mesmo tempo em que o fotojornalista supostamente correria risco ao entrar "na jaula com os bichos", com suas vasilhas de restos de carne, ele está seguro lá dentro. A suposta neutralidade da mídia compõe a cena de forma ambígua. Na capa do jornal, a manchete "Índios Tembé continuam reféns" mostra uma situação tensa, mas, contraditoriamente, banal. O fotógrafo está pacificamente dentro do galpão de cárcere e o texto da matéria não trata a questão como uma violação dos direitos humanos que precisava ser resolvida com urgência. Muito pelo contrário, ainda gera uma ambiguidade sobre quem eram os donos da terra invadida e se aquela "punição" não era realmente merecida.

As fotografias dos conflitos em que estão envolvidos os povos indígenas só há muito pouco tempo, com as condições de possibilidade proporcionadas pela Web e com a organização cada vez mais forte do movimento indígena ganharam visibilidade para a opinião pública. Provavelmente, também por isso, elas não foram tomadas com muita frequência como objeto de análise de pesquisadores brasileiros. Diferente do que acontece nos cadernos de polícia, o interesse acadêmico muitas vezes se comprometeu em mostrar aquilo que nossos olhos veem sem estranhamento.

\section{Considerações Finais}

A conexão dessas "simples práticas" com modos de discurso, formas de vida, ideias do pensamento e figuras da comunidade não é fruto de nenhum desvio maléfico. Em compensação, o esforço para pensá-la implica abandonar a pobre dramaturgia do fim e do retorno, que não cessa de ocupar o terreno da arte, da política e de todo objeto de pensamento. Jacques Rancière

Sabemos que a produção do discurso pode ser controlada, selecionada, organizada e redistribuída por um certo número de procedimentos e sistematizações 
formais (FOUCAULT, 2000). Dessa forma, a irrupção de alguns acontecimentos pode ser sujeitada, mascarada, ou até apagada, em benefício de uma recursividade das estruturas fixas, dentro de um discurso hegemônico e totalizador, como o da ciência tradicional ou o da mídia com suas hierarquias e classificações.

A fronteira entre o dizível e o indizível, o confessável e o inconfessável, separa uma memória coletiva subterrânea da sociedade civil dominada ou de grupos específicos, de uma memória coletiva organizada que resume a imagem que uma sociedade majoritária ou o Estado desejam passar ou impor (POLLAK: 1989, p.8).

Assim, saberes de pessoas anônimas, saberes locais, ou de grupos historicamente desfavorecidos que estão em desacordo com a ordem e a lógica estabelecida, são sistematicamente hierarquizados e desqualificados, de um lado, e manipulados e controlados, de outro, em favor de algo universal que segue com sua contínua temporalidade (FOUCAULT, 2008). O acontecimento, estigma da dispersão temporal, que desmascara e abala a elaborada continuidade de um discurso tradicional, como faz a versão Tembé sobre a Batalha do Livramento, é, hoje, um dos principais elementos de uma nova análise histórica.

A possibilidade de novas formas de análise, aquelas que não se apoiam em nenhuma constância, permite que se faça ressurgir o acontecimento no que ele tem de único e agudo. A irrupção de um acontecimento está na categoria do acaso. Não há como impedir, definitivamente, por mais poderosos que sejam os poderes delineadores das ordens discursivas, que outras verdades emerjam, quando modificadas as condições de possibilidades de se enunciar a história.

Em relação à história dos Tembé, muitos acontecimentos precisaram ser silenciados sob pena de novas sanções a esta sociedade por parte das políticas públicas. Com a organização nacional do movimento indígena e as transformações políticas no Brasil de 1988 até 2016, houve uma mudança na legislação e nas práticas estatais que acenaram com novas possibilidades de visibilidade das versões Tembé sobre a história do contato.

É preciso entender por acontecimento não uma decisão, um tratado, um reino, ou uma batalha, mas uma relação de forças que se inverte [...]. As forças que se encontram em jogo na história não obedecem nem a uma destinação, nem a uma mecânica, mas ao acaso da luta. (FOUCAULT, 2014, p.73)

A história "efetiva", como queria Foucault (2007), deve lançar olhares ao que está próximo, a partir de um ângulo que perscrute as decadências, os acontecimentos 
mínimos, e olhe os saberes mais desqualificados. A noção de acontecimento, portanto, para Foucault (2008), sendo a emergência de determinações históricas casuais que se opõem à origem teleológica de uma metafísica ou ao sujeito de um estruturalismo unitário, deve servir de princípio regulador para a análise das redes de memórias, dos feixes dos discursos, das relações de poder e da luta na trama histórica que costura o presente.

Ainda hoje, quando os Tembé saem para fiscalizar a extração da madeira dentro da TIARG, quase sempre essas iniciativas terminam em missões (como os Tembé chamam o enfrentamento armado). Ao chegarem nesses pontos escondidos dentro da floresta, eles esbarram com os exploradores armados que protegem a madeireira clandestina. Além disso, há também os colonos invasores, que já moram dentro da TIARG há mais de quarenta anos.

As táticas utilizadas pelos Tembé, através das suas narrativas de contato, das suas histórias de batalha, atuam nos interstícios desse 'lugar' já controlado por um poder hegemônico e proprietário. A desocupação da fazenda Mejer, após quase 40 anos de luta na justiça, e os constantes e atuais conflitos com colonos invasores, é o resultado de um contínuo estado de guerra, mesmo dentro da Terra Indígena, homologada e demarcada pelo governo brasileiro. Mesmo dentro de seu território os Tembé ainda atuam nas brechas.

\section{Referências}

FOUCAULT, Michel. A arqueologia do Saber. Rio de Janeiro: Forense Universitária, 2008.

. A Microfísica do Poder. São Paulo: Graal, 2007.

. A Ordem do Discurso. São Paulo: Edições Loyola, 2000.

. Em defesa da sociedade. Trad. M. E. Galvão. São Paulo: Martins fontes,

1999.

GREGOLIN, Maria do Rosário. Analise do discurso e semiologia: enfrentando as discursividades contemporâneas. In: Piovezani, Carlos; Carcino, Luzmara; Sargentini, Vanice (Org.). Discurso, semiologia e história. São Carlos: Claraluz, 2011, p. 83-105.

HALBWACHS, M. A Memória Coletiva. São Paulo: Centauro, 2006.

MUXI, Sérgio. Entrevista. UFPA, 2013.

NEVES, Ivânia; CARDOSO, Ana Shirley Penaforte. Patrimônio Cultural TembéTenetehara. Belém: IPHAN, 2015.

NEVES-CORREAA, Maurício. Tese de doutorado: Heterotopias no país do milagre: os corpos indígenas e as histórias filmadas. Unesp. Araraquara, SP, 2018. 
NIETZSCHE, Friedrich. Para Genealogia da Moral. In: Friedrich Nietzsche Obras Incompletas. São Paulo: Editora34, 2014. (Coleção Fábula)

PEREIRA GOMES, Mércio. $O$ índio na história. $O$ povo Tenetehara em busca da liberdade. Petrópolis, Vozes, 2002.

POLLAK, Michael. Memória, Esquecimento, Silêncio. Estudos Históricos. Rio de Janeiro, vol.2, no 3, 1989.

RANCIÈRE, Jacques. A partilha do sensível. São Paulo: Editora 34, 2005.

TEMBÉc, América. Entrevista. Aldeia Sede - TIARG, 2015.

TEMBÉb, Edmilson. Entrevista. Aldeia Sede - TIARG, 2015.

TEMBÉ, Naldo. Entrevista. Aldeia Sede - TIARG, 2014 - 2015. 